\title{
A Diversidade de Ideias, Pessoas e Caminhos na Construção do Grande Espaço Coletivo que é a Escola
}

\author{
Mariana Benchimol * \\ Fabíola Guadix **
}

\begin{abstract}
Resumo
A Escola Comunitária Cirandas foi fundada em 2014 com o intuito de construir um projeto de transformação social através da educação. Atualmente, recebe 53 crianças agrupadas em um único ciclo, equivalente do $1^{\circ}$ ao $5^{\circ}$ ano do Ensino Fundamental. O processo de ensino e aprendizagem realiza-se através de pesquisas e projetos idealizados pelas crianças, em parceria com toda a comunidade escolar. Não temos provas, notas ou uniformes. Acreditamos no diálogo como base para a construção coletiva do conhecimento, assim como valorizamos diferentes formas de saber e aprender. A metade dos alunos tem bolsas escolares, na intenção de construirmos um ambiente sociodiverso. A diversidade social permite amplitude nas relações sociais, na visão de mundo e na formação integral do ser humano.

Palavras-chave: ciclo, diversidade, educação, transformação, inovação.
\end{abstract}

The Diversity of Ideas, People and Ways to Build Up the Big Colective Space Such as the School

\section{Abstract}

The Cirandas Communitarian School has been created in 2014 to be a project for social transformation through education. Nowadays, there are 53 children in just one cycle, corresponding the five first years of the primary school. The teaching and learning process goes through researches and projects idealised by children, togetherness with the roll scholar community. There are no tests, grades or uniforms. We believe in dialogue as basement for the construction of the knowledge, such as we valorise different kinds of wisdom and learning. Half of the students have scholarships, with the intention to build a socio diverse environment. The social diversity enlarges social relationships, open mind and helps the integral education of the humans.

Key words: cycle, diversity, education, transformation, inovation.

\footnotetext{
Diretora do Inst. Oju Moran e Vice-Diretora da Escola Comunitária Cirandas. E-mail: mariana@ojumoran.org

** Diretora da Escola Cirandas. E-mail: fabiola@ojumoran.org
} 


\section{Fundamentos Iniciais}

A Escola Comunitária Cirandas, localizada em Paraty- RJ, foi fundada no início de 2014 com a intenção de ser um projeto educativo para a transformação social. A raiz da proposta pedagógica está na diversidade de pessoas, ideias e caminhos. Ou seja, a escola nasce fundamentada em valores, não em uma prática ou método pedagógico definido. Partimos do princípio que Paulo Freire (1996) coloca em diversas obras, como no livro Pedagogia da Autonomia, em que a educação precisa dialogar com a realidade da comunidade. Por acreditarmos que a comunidade está em constante transformação, tanto no que se refere ao fluxo de pessoas, quanto ao desenvolvimento individual do ser humano, precisamos ter uma escola que sempre repense sua prática, para que mantenha um sentido vivo.

Começamos o processo de construção da escola antes de sua abertura. Nesta época, avaliamos o modelo tradicional de ensino como ineficiente. Este modelo nasce junto com a Revolução Industrial e baseia-se no melhor aproveitamento financeiro dos recursos humanos escolares e na padronização do adulto, para que esteja adaptado a um mercado de trabalho pouco reflexivo. Em outras palavras, organizou-se um modelo de escola onde um professor é capaz de passar certo conteúdo para um grupo grande de alunos através de livros e apostilas, que não necessariamente dialogam com os interesses e necessidades da turma. A escola passa a ser um espaço de preparar o adulto para a vida, para ser capaz de ser um trabalhador. Esquece-se que a escola já é a vida e que o mercado de trabalho é somente uma parte da vida do adulto. Certamente, estar preparado para o mundo do trabalho é fundamental. Mas, que tipo de trabalhador pretende-se formar é ponto central nesta questão.

Esta forma passiva de aprender é intenção do modelo tradicional, mesmo que isso não esteja presente nos discursos escolares dos tempos de hoje. Agravando este cenário, precisamos nos atentar aos acontecimentos das últimas décadas, onde os conteúdos acadêmicos estão democratizados na internet e as trocas humanas são cada vez mais constantes através dos incrementos da comunicação e da circulação de pessoas. Com isso, acreditamos que a intenção da escola deva ser o aprender a aprender, ou seja, aprender a pesquisar e olhar criticamente para um conteúdo, relacionando-o com o local e o global. "Na escola, não devemos aprender para saber, mas aprender para que, na vida, sempre possamos aprender" (STEINER, 2011).

Neste modelo, também, dificilmente há espaço para diferentes formas de ensinar e aprender, pois o livro ou apostila já indica um caminho. Então, surgem as perguntas: como se pode acreditar que as pessoas ensinam e aprendem de uma única 
forma, se elas são diferentes? Como um conteúdo predeterminado, por melhor que seja, pode fazer sentido para qualquer comunidade escolar? Como o educador pode ter autonomia, se está preso a uma apostila ou a uma grade curricular? Como um grupo consegue aprender junto uma matéria se cada um tem um ritmo diferente de aprendizagem?

A partir destas perguntas, construímos os nossos "não objetivos", ou seja, o que não queremos na escola. Desejamos um processo de ensino-aprendizagem individualizado, que faça sentido para a criança e sua comunidade, que se relacione com a vida prática.

Visitamos diversas escolas em busca de inspiração, conscientes de que a cópia de qualquer modelo, por mais eficiente que seja, não faria sentido, uma vez que a comunidade da Escola Cirandas é única. Tampouco, não começamos como estamos hoje e não pretendemos seguir como estamos fazendo. Nossa intenção está na simplicidade das palavras de Paulo Freire (1996): ação - reflexão - ação. Agimos, refletimos/ avaliamos a ação e refazemos nossa prática, mantendo ou transformando o que está em curso.

Hoje, a Escola Comunitária Cirandas organiza seu currículo em um único ciclo, que corresponde do primeiro ao quinto ano do Ensino Fundamental, com crianças entre 6 e 12 anos. A organização em ciclos associada à aprendizagem através de projetos e pesquisas de interesse das crianças rompe com a fragmentação de tempo e áreas de conhecimento impostas pela tradicional organização por séries e matérias. No ciclo, a intenção pedagógica flui no ritmo de cada criança, sem haver homogeneidade na forma de aprender e tampouco na ordem que cada assunto aparece na vida escolar.

Os projetos e pesquisas escolhidos pelas próprias crianças geram a oportunidade de trabalhar com seus interesses e com o conhecimento prático. Assim, a velha lógica da escola tradicional que traz o conhecimento teórico na escola, para que, um dia, esse conhecimento seja aplicado à vida prática (e muitas vezes isso nunca ocorre) é invertida. Saímos do conhecimento prático (projetos e pesquisas) para o conhecimento teórico, trazendo sentido à aprendizagem e possibilitando um processo ativo de construção do conhecimento.

Os projetos e pesquisas são de livre escolha das crianças e os educadores não tem como dominar todas as áreas de conhecimento. Deste modo, contamos com mediadores, que são voluntários com conhecimento técnico sobre cada projeto ou pesquisa escolhido pela criança. O papel do educador escolar é de vincular esse conhecimento técnico ao processo de ensino-aprendizagem curricular, garantindo que o pensamento da criança seja complexibilizado através do diálogo para permitir a rela- 
ção da vida prática com a teoria.

Morin et. al. (2009) diz que os conhecimentos de mundo são infinitos e o que chega à cada um está ligado ao seu destino. O papel do educador é manter um diálogo ativo, relacionando o interesse da criança com o desenvolvimento cognitivo, psicossocial e físico-motor. Neste processo, fazemos ativo o dever da escola de Ensino Fundamental em desenvolver saberes acadêmicos básicos, como aprender a ler, escrever e interpretar; as quatro operações matemáticas e o raciocínio lógico.

Mais importante que a organização em ciclos e o ensino-aprendizagem através de pesquisas e projetos é a forma como esse processo é conduzido. Afeto, acolhimento, alegria e interesse são pontos centrais, que jamais podem ser esquecidos no ambiente escolar. O prazer em aprender e a curiosidade pelo mundo devem ser cultivados como quesitos elementares, que dão base para qualquer ambiente.

\section{A Política de Bolsas}

A Escola Comunitária Cirandas tem 50\% dos seus estudantes com bolsas escolares. Destes, no mínimo a metade tem bolsas integrais e, no máximo, a outra metade tem bolsas parciais. Para receber uma bolsa, a família da criança passa por um criterioso processo, onde avalia-se a renda, a rede de apoio familiar, situações de risco da criança e da família, escolaridade dos familiares, entre outros. Para receber uma bolsa integral, temos 2 critérios: que cada membro da família tenha, no máximo, 2/3 do salário mínimo como renda e a escolaridade dos pais seja, no máximo, o Ensino Médio.

A intenção da Política de Bolsas é constituir uma comunidade escolar heterogênea, com representantes de diversas origens socioeconômicas e culturais, pois assim é o mundo. De um modo geral, vemos que as escolas possuem comunidades homogêneas, com moradores do entorno, condições socioeconômicas e valores parecidos. Nestes casos, é mais simples realizar a comunicação com a comunidade e entender o que é a realidade de vida dos educandos. Na Cirandas, não há um padrão na comunidade. O convívio em um ambiente sociodiverso traz riqueza para nossos processos e discussões.

A base conceitual para a Política de Bolsas é o livro Pedagogia do Oprimido, de Freire (1987). Neste livro, o autor explica a organização das relações sociais em nosso país entre opressores (detentores do saber e do poder) e oprimidos (que devem seguir as regras dos opressores e tem desejo de melhorar de vida para se tornarem opressores). Assim, constrói-se um círculo vicioso repleto de preconceitos e distorções de 
valores humanos.

Quando trazemos a diversidade para a escola, trazemos este conflito social histórico e velado para o processo pedagógico. Não temos a intenção de resolvê-lo, mas sim de ter a oportunidade de dialogarmos sobre os diversos conflitos que surgem e se fundamentam nesta relação entre opressores e oprimidos. O diálogo, o respeito, a empatia e o altruísmo são bases da transformação que desejamos.

O desafio não é fácil; sabemos que as crianças carregam os valores de suas famílias e que, nesta fase, ainda não tem sua moralidade constituída. Nossa crença fundamenta-se no convívio diário com o diferente, na construção de amizades e vínculos que independam da situação socioeconômica de cada um. Para isso, a ação pedagógica valoriza diversas formas de saber, não só o saber acadêmico, o mundo dos letrados; mas também a oralidade, o saber fazer, os trabalhos manuais e as artes. Todos esses saberes compõem nossa sociedade e enriquecem a integralidade humana.

Ressaltamos que, de acordo com Koepke (2014), a moralidade da criança chega em torno de nove anos. Com isso, lidamos com crianças em uma fase muito importante de suas vidas, quando questionam o mundo que receberam de forma passiva para ver se é digno de sua admiração. Antes de ter condição real de agir com moralidade, a criança age por imitação. Os adultos são espelhos da verdade. Quando adquirem a capacidade de compreender o valor moral de cada ação, testam os adultos e o mundo para perceberem se a confiança cega que depositaram antes merece, realmente, sua admiração.

\section{Inclusão}

Trabalhar com inclusão sempre foi uma premissa. Se desejamos um ambiente sociodiverso, não nos referimos somente as diferenças socioeconômicas, mas também culturais e a inclusão de pessoas com deficiência. Como nosso processo de ensino e aprendizagem é pautado no indivíduo, torna-se mais tranquila a integração das crianças com deficiência.

Contudo, percebemos que nosso processo pedagógico é excessivamente reflexivo para parte das crianças com deficiência, que de maneira geral, se beneficiam mais com formas diretivas de ensino. Buscamos, na medida do possível, construir currículos adaptados e realizar trabalhos distintos com os estudantes com deficiência, oferecendo-lhes conteúdos mais tradicionais e, na medida de cada um, envolvendo-os em pesquisas e projetos. Percebemos que quando há uma parceria com as famílias e quando estas tem acesso a uma rede médica especializada, os progressos cognitivos 
são mais expressivos.

De todo modo, quem mais se beneficia com a presença dos alunos com deficiência são aqueles sem deficiência. Impressiona a capacidade de irradiar compaixão e solidariedade em todo o ambiente escolar.

\section{Avaliação Escolar}

Um processo de avaliação é sempre arbitrário. $\mathrm{O}$ avaliador escolhe o quê e como avaliar. Estamos acostumados com avaliações organizadas em testes e provas, com questões objetivas ou discursivas que são corrigidas e geram um conceito ou uma nota. Uma mesma criança pode ter notas ou conceitos discrepantes, dependendo de como foi avaliada.

Na Escola Comunitária Cirandas entendemos que a avaliação deve ser processual, ou seja, ocorre o tempo todo. O educador sabe em que nível está cada criança e propõe atividades que partem do nível de cada um para um novo desafio, como propõe Vygotsky (1993) no conceito de Zona de Desenvolvimento Proximal. Entendemos que a produção infantil ocorre por meio de hipóteses de acerto e, deste modo, devem ser sempre valorizadas. Quando uma criança, em seu esforço de acerto, produz algo que não condiz com uma verdade (com a língua padrão, por exemplo), ela está em seu caminho individual de aprendizagem e quanto mais se sentir segura para seguir neste processo, mais chances terá de alcançá-lo com êxito. Este conceito é amplamente discutido por Emília Ferreiro e Ana Teberosky no livro Psicogênese da Língua Escrita e serve como uma forte base na Escola Cirandas.

Nosso esforço está em manter a autoestima e a vontade da criança em aprender, tendo como pano de fundo a função social da aprendizagem. Para que eu aprendo? Por que eu aprendo? Onde coloco meu conhecimento no mundo?

Jamais pegamos uma produção de uma criança e grifamos com caneta vermelha "certo" ou "errado". Essa produção serve como uma avaliação do nível da criança para que ela possa ser desafiada a seguir aprendendo, com vontade, curiosidade.

Realizamos o monitoramento deste desenvolvimento através de anotações individuais, uma espécie de diário de bordo do educador. A avaliação da criança ocorre três vezes por ano de forma discursiva em relatórios, onde todos os educadores que lidaram com o estudante relatam os principais acontecimentos cognitivos, sociais, emocionais e físico-motores. Trata-se de um processo trabalhoso, mas que traz mais elementos sobre como está cada criança, sem necessariamente classificá-la como boa ou ruim. Acreditamos que as crianças "estejam" e não "sejam” alguma coisa. Elas estão 
se transformando, dia a dia, e nossa intenção nos relatórios de avaliação é mostrar como estão naquele momento.

\section{Nossos Valores}

A Escola Comunitária Cirandas é um espaço dinâmico e orgânico, em constante transformação, onde toda comunidade participa e contribui, ancorada em valores: respeito, amor, confiança e diversidade. Estes valores foram construídos coletivamente e permeiam as ações pedagógicas. Quando nos referimos a valores, tratamos de algo que não abrimos mão; é aquilo que enraíza nossos ideais.

\section{O Currículo Escolar}

No início de 2016, ou seja, na entrada do terceiro ano de vida da Escola Comunitária Cirandas, reconstruímos o currículo escolar. O currículo contém diferentes formas de saber, somando-se aos acadêmicos. Analisamos o mundo e percebemos que temos dificuldade em construir boas relações humanas e entendemos que, se a escola é um espaço de intensas construções de relações, precisamos de um currículo que abarque esta demanda. O conhecimento acadêmico (português, matemática, ciências, história, geografia, artes e educação física) se soma a áreas que chamamos de Vida Prática, Relações e Autoconhecimento, por exemplo.

Um currículo traz escolhas importantes, baseadas em valores e no caminho que queremos seguir com toda a comunidade escolar. Assim, colocamos dentro dele, como objetivos pedagógicos, o que julgamos ser significativo em nossa prática. Hoje, o currículo da Cirandas está dividido nos seguintes saberes: Língua Portuguesa; Matemática; Ciências Humanas e Biológicas; Artes e Cultura Popular; Línguas, Cultura e Identidade; Brincar, Corpo e Movimento; Vida Prática; Relações e Autoconhecimento.

Trazer para dentro do processo de aprendizagem e para dentro de um documento formal, como é o currículo, assuntos como Autoconhecimento ou Relações é um desafio tremendo. Eles exigem processos profundos que vão muito além de técnicas para se ensinar a ler e escrever ou fazer contas. Precisamos acessar outras áreas do conhecimento, além da Pedagogia, para nos dar suporte. E mais, precisamos, como educadores estar abertos a repensar nossa própria maneira de agir, sentir e pensar.

Costumamos dizer na Cirandas que devemos ser aquilo que queremos ver nas crianças. Tudo isso requer muita entrega de cada educador e muito estudo prático e teórico. Desta forma, temos um grupo de estudos aberto, onde a cada semana um 
participante apresenta um estudo (teórico e/ou prático), finalizando com uma roda de conversa. É um momento extremamente rico de troca e formação. Além disso, a equipe de educadores participa de programas de formação continuada apoiados pelo mantenedor da escola, o Instituto Socioeducativo Oju Moran (www.ojumoran.org). Portanto, educadores e educandos seguem estudando continuamente.

O currículo da Cirandas foi escrito de uma forma simples e enxuta para que toda a comunidade escolar possa conhecê-lo, entendê-lo e apropriar-se dele. É um documento que deve ser constantemente revisitado para que avaliemos se faz sentido.

\section{O Período Integral e o Ritmo Escolar}

Quando optamos por trabalhar em ciclos e com uma proposta pedagógica dialógica, em que não damos diretamente a resposta à criança e sim a ajudamos a buscá-la, precisamos de tempo. O processo reflexivo exige calma. Assim, adotamos o período integral no horário escolar. De acordo com a realidade da comunidade escolar, escolhemos um horário flexível: de 8:00h às 15:20h há o desenvolvimento do currículo (horário obrigatório) e entre 15:30h e 17h há o horário estendido (opcional e aberto a qualquer criança da cidade). Outro ponto fundamental para a adoção do período integral é a proposta social da escola, pois muitas famílias precisam que as crianças estejam na escola o dia todo.

Para que este período flua de forma saudável, buscamos estabelecer um ritmo que intercala atividades introspectivas com atividades expansivas, como uma respiração. Ao chegarem à escola, as crianças realizam uma atividade de harmonização, para despertar o corpo, a mente e conectar as energias (rodas rítmicas, alongamentos, meditação, tai chi chuan, entre outros). Logo, se encaminham para as atividades mais cognitivas nas salas de Projeto e Pesquisa ou Iniciação (para aqueles que estão bem no início do processo de alfabetização).

No meio da manhã, há um lanche preparado na escola e brincam livremente por cerca de uma hora. Outras ações fecham o período da manhã, como biblioteca, bastão da palavra e finalização de trabalhos. Entre 12:10h e 13:40h, almoçam, lavam seus utensílios e brincam livremente. A cada dia, uma equipe ajuda na arrumação da cozinha e outra no cuidado com o galinheiro (projeto das crianças). No restante da tarde, temos quatro atividades acontecendo diariamente. Durante um semestre, cada criança faz uma atividade fixa por dia, escolhida por ela e, em alguns casos, indicada pela equipe pedagógica. As atividades são: música, educação física, inglês, educação alimentar/culinária, modelagem, pintura, teatro, dança/expressão corporal, desenho e 
educação ambiental (aulas de trabalhos manuais acontecem pela manhã).

Após o horário curricular, entre 15:20h e 17h, a escola recebe oficineiros (como exemplo: capoeira, skate, francês, teatro, xadrez, etc.) e educadores do programa de Residência Educativa, em que oferecemos hospedagem para educadores de fora de Paraty em troca de desenvolverem atividades com as crianças neste horário.

A intenção da Escola Comunitária Cirandas é ter suas portas abertas para interagir cada vez mais com a comunidade em geral. Por isso, no período da noite acontecem oficinas para adultos e manifestações da Cultura Popular, como dança afro, tambor de crioula, capoeira e francês. Acreditamos que, desta maneira, enriquecemos as relações e trazemos diferentes saberes para dentro da escola.

\section{O Modelo de Gestão}

A Escola Comunitária Cirandas tem um modelo de gestão próprio, composto por níveis deliberativo, consultivo e executivo. O nível deliberativo é composto por cinco membros: dois pais (escolhidos pelos pais), duas pessoas da equipe (escolhidas pela equipe, das quais uma é sempre o Diretor) e um membro do Instituto Oju Moran - IOM, mantenedor da escola (escolhido pela diretoria do IOM). Todos os representantes são eleitos através de um método chamado Sociocracia, que é um modelo baseado em argumentos, não em número de votos.

O nível consultivo é representado no Fórum Escolar. Trata-se de uma reunião aberta a qualquer interessado, com pauta aberta, onde se discute assuntos diversos sobre a escola. O Fórum Escolar ocorre com periodicidade mínima a cada dois meses. $\mathrm{O}$ nível executivo é composto pela equipe escolar, pais voluntários, oficineiros, residentes educativos e estudantes.

Este modelo fundamenta-se no diálogo e em uma estrutura em círculos, onde pessoas legitimadas representam os diferentes pontos de vista da escola e tem possibilidade de uma participação ativa e dinâmica.

\section{Monitoramento e Avaliação}

A escola realiza um trabalho de Monitoramento e Avaliação (M\&A) desde sua abertura. Este trabalho tem a intenção de colher a opinião dos diferentes atores escolares para avaliar ações e resultados deste projeto. Para a realização do M\&A, anualmente é realizado o mesmo processo: o Conselho Gestor realiza um planejamento estratégico, contendo objetivos, metas (ações a serem realizadas em um determinado 
tempo) e resultados esperados. Este planejamento é compartilhado com a comunidade que constrói perguntas avaliativas para as ações e resultados, criando indicadores de processo e de resultado.

Atualmente, há sete questionários distintos que são aplicados a cada semestre para: equipe, educadores de projeto/pesquisa ou iniciação, pais, tutores, diretores, oficineiros e crianças. Os resultados são compilados e socializados através de um relatório e reuniões avaliativas. Nestas reuniões, avaliamos os resultados do relatório e o próprio processo de M\&A.

Mesmo tratando-se de uma ferramenta limitada e fria, onde não há tom de voz ou calor humano, é possível ter uma boa noção sobre a opinião da comunidade a respeito da escola, corrigir caminhos e seguir confiante.

\section{Escola como Espaço Comunitário}

Acreditamos na escola como espaço comunitário por entendermos que cada indivíduo é um educador no momento que se relaciona saudavelmente com o outro. Assim, quanto mais pessoas interessadas em trocas de saberes tivermos na escola, mais rico será o processo de ensino-aprendizagem de todos. A escola é local de encontro, de ideias, de construções; é lugar de aprender e ensinar; é um local de trocas. A palavra central neste processo é acolhimento. As pessoas precisam sentir-se bemvindas.

Este movimento estende-se para fora dos muros. Buscamos nos espaços públicos e privados da cidade o conhecimento de mundo. Trata-se de abrir as portas da escola para a circulação comunitária, para dentro e para fora do espaço escolar. Trata-se de entender a cidade e seus cidadãos como parte integrante de todo o processo pedagógico.

Quanto mais vivenciamos o dia a dia de uma escola viva, trazemos para o processo pedagógico aspectos pertinentes da vida prática e percebemos a importância de uma real construção coletiva do espaço. A escola é de todos e para todos que dela fazem parte. Assim, a responsabilidade também é coletiva. Sem dúvida, existem diferentes níveis de responsabilidade, mas o espírito colaborativo permeia todas as ações. Nesse sentido, escola e família passam a estar interconectadas na construção coletiva do projeto. Na Cirandas, não existe escola sem a parceria das famílias. O espaço de diálogo e convivência entre educadores escolares e famílias não se resume a reuniões com objetivos estabelecidos, mas a festas, eventos, acampamentos, piqueniques, caminhadas na mata, mutirões, entre outros. 
Em uma escola comunitária, alguns processos são longos por conta de tomadas de decisão em grupo. Mas, acreditamos que neste caminho podemos nos tornar uma Comunidade de Aprendizagem.

\section{Esperanças de um Futuro}

Os resultados deste projeto já são observados no ambiente escolar. Vemos crianças felizes, interessadas em pesquisar e realizar projetos. Vemos a estima de muitos estudantes, antes abalada em outras escolas, aumentada e fortificada. Vemos crianças que refletem sobre o mundo, que não se importam com notas ou avaliações e que seguem desejando aprender.

Convivemos com pais e educadores entusiasmados, que se doam para a escola além do esperado. Convivemos com educadores e pais de outras escolas, que participam das atividades da Cirandas com entusiasmo e alegria. Somos presenteados, dia a dia, com a nossa transformação pessoal.

Sempre nos questionam como será o processo de adaptação dos estudantes da Cirandas em outras formas de ensino. Esta resposta só virá com o tempo. Mas, acreditamos que um ser humano bem estruturado, confiante de sua capacidade de aprender e agir no mundo, será capaz de seguir seu caminho em outros ambientes sem maiores dificuldades. Um processo de adaptação é necessário em qualquer troca de ambiente, nada além disso. Seguimos firmes no propósito de plantar uma pequena semente de transformação social através da educação.

\section{Referências}

FERreiro, E. E TEBEROSKY, A. Psicogênese da Língua Escrita. Porto Alegre: Artmed. 1999.

FREIRE, P. Pedagogia da Autonomia: saberes necessários à prática educativa. São Paulo: Paz e Terra, 25. ed., 1996.

Pedagogia do Oprimido. Rio de Janeiro: Paz e Terra, 17. ed., 1987.

KOEPKE, H. A Criança aos 9 Anos: a queda do paraíso. São Paulo: Antroposófica, 2014. 
MORIN, E., CIURANA, E.R. e MOTA, R. D. Educar na Era Planetária: pensamento complexo como método de aprendizagem pelo erro e incerteza humana. São Paulo: Cortez, Brasília, DF: UNESCO, 2009.

STEINER, R. Os Pontos Centrais da Questão Social. São Paulo: Antroposófica, 2011.

VYGOTSKY, L. R. E LURIA, A. R. Sutudies on The History of Behavior: ape, primitive, and child. Hillsdale NJ: Lawrence Erlbaun Associate. 1993.

Recebido em: 10 abril 2016.

Aceito em: 21 abril 2016. 